\title{
WEB-BASED COMPUTER ASSISTED DESIGN UNTUK DIMENSI BANGUNAN SALURAN IRIGASI
}

\section{(Web-Based Computer Assisted Design for Irrigation Channel Building Dimensions)}

\author{
Nurmila $^{1 *)}$, Ahmad Munir ${ }^{2)}$, dan Suhardi ${ }^{3)}$ \\ ${ }^{1)}$ Program Studi Teknik Pertanian, Universitas Hasanuddin, Makassar \\ ${ }^{2}$ Program Studi Teknik Pertanian, Universitas Hasanuddin, Makassar \\ ${ }^{3}$ Program Studi Teknik Pertanian, Universitas Hasanuddin, Makassar \\ *) Email korespondensi: nurmilamila2014@yahoo.com
}

\begin{abstract}
ABSTRAK
Di era digital saat ini, hampir seluruh kegiatan masyarakat menggunakan internet dalam memenuhi kebutuhannya. Sama halnya dalam bidang pertanian, diperlukan sebuah media yang dapat diakses oleh masyarakat yang dapat memberikan informasi mengenai perencanaan dimensi saluran. Dengan adanya web assisted design ini, diharapkan dapat memudahkan dalam perencanaan dimensi saluran. Website ini dibangun berdasarkan metode Web Development Life Cycle (WDLC) yang meliputi tahapan website planning, analisi kebutuhan, tahapan pengembangan web, dan implementasi. perangkat lunak yang digunakan untuk membangun dan menjalankan web ini yaitu visual studio code, server yang digunakan adalah Apache dan browser berupa Chrome 28.0.1469.0. Bahasa pemograman yang digunakan yaitu javascript dengan bahasa markup HTML. Web assisted design ini terdiri dari 6 menu yaitu home, kalkulator, referensi, konversi, bantuan, dan Tentang. Dengan menginput nilai debit rencana, maka menghasilkan nilai luas penampang saluran dengan nilai koefisien Manning. Dengan nilai koefisien ini maka dapat ditentukan bahan saluran yang digunakan dalam pembangunan saluran. Menu kalkulator menghitung luas penampang saluran baru, keliling basah, dan jarijari hidrolis. Dimensi saluran yang dihasilkan dapat diaplikasilan pada perencanaan dimensi saluran irigasi yang ekonomis.
\end{abstract}

Kata Kunci: Website, Dimensi Saluran, Sistem Informasi, Kalkulator.

\section{PENDAHULUAN}

\section{Latar Belakang}

Pembangunan irigasi adalah suatu cara yang dilakukan untuk menunjang pembangunan petanian. Pembangunan irigasi dapat dilakukan melalui pembangunan saluran irigasi baik perbaikan, pemeliharaan serta peningkatan dan pengelolaan saluran irigasi.

Irigasi adalah suatu bentuk kegiatan dalam penyediaan, pengambilan, pembagian, pemberian dan penggunaan air untuk kegiatan pertanian dengan menggunakan satu kesatuan saluran. Petani ataupun masyarakat perlu untuk mendapatkan informasi mengenai keadaan saluran baik keadaan bangunannya maupun teknik untuk membuat saluran yang dapat digunakan secara baik oleh semua pihak. Sistem informasi yang berisi tentang bangunan irigasi sangat dibutuhkan karena akan sangat membantu dalam pengembangan pembangunan saluran irigasi.

Menurut Kamiana (2011), dalam perencanaan irigasi banyak pertimbangan yang harus diperhatikan. Terdapat empat data yang mesti digunakan dalam perhitungan debit rencana, yakni data 
topografi dan data tata guna lahan, data iklim, data curah hujan, serta data debit. Sehingga dalam perencanaannya perlu analisis yang kuat untuk melaksanakan pembangunan tersebut.

Dalam pengembangan sistem informasi saat ini diperlukan pengembangan dalam bidang teknologi informasi dalam menyampaikan masalah perencanaan kepada petani maupun pihak pertanian. Penyajian rumus dalam bentuk informasi berbasis web akan sangat memudahkan karna berbagai ukuran dimensi akan tersedia sesuai dengan standar hidrologi dan ekonomi. Dengan melakukan penyajian rumus berbasis web, maka informasi yang disajikan bisa berbentuk data teks, gambar, animasi dan suara. Selain itu, informasi tersebut dapat diakses oleh komputer lain yang terhubung internet.

Kurangnya sistem informasi berbasis web, membuat penulis untuk dapat merancang web yang dapat memberikan informasi mengenai bangunan irigasi khususnya bangunan saluran dengan penampang trapezium, dan segiempat dengan mempertimbangkan perencanaan ekonomisnya.

\section{Tujuan dan Kegunaan}

Tujuan dari penelitian ini yaitu mendesain web menjadi suatu sistem perhitungan dimensi saluran pada bangunan irigasi.

Kegunaan penelitian ini adalah memberikan informasi dalam bentuk web agar perancang atau masyarakat umum lebih mudah dalam perencanaan dimensi saluran irigasi. Memberi alternative dalam membuat website yang lebih dekat pada perancangan dimensi saluran ekonomis.

\section{METODE PENELITIAN}

\section{Alat}

Alat yang digunakan dalam penelitian ini berupa perangkat keras yang akan digunakan untuk membangun web adalah laptop dengan spesifikasi AMD +2400. Sistem operasi Windows 8.1, perangkat lunak yang digunakan untuk membangun dan menjalankan program yaitu, visual studio code sebagai script pembuatan program. Map server digunakan untuk mengeksekusi program di web server. Browser engine: Mozilla 5.0, dan Chrome 28.0.1469.0, perangkat lunak untuk implementasi dan pengujian sistem

\section{Bahan}

Bahan yang digunakan dalam pembuatan website ini yaitu data-data sekunder dan informasi yang diperoleh dari studi pustaka (buku, hasil penelitian, data statistik).

\section{Prosedur Penelitian \\ Perencandan Implementasi}

Rancangan sistem yang dilakukan dalam penelitian ini yaitu berdasarkan metode Web Development Life Cycle (WDLC) yang meliputi tahapan sebagai berikut:

\section{Perencanaan Web}

Tahapan ini mencakup beberapa kajian yang akan dilakukan terhadap permasalahan dan pengembangan web yang akan dirancang yaitu:

1. Penentuan tujuan, sasaran pengembangan dan konfigurasinya.

2. Teknologi yang digunakan

3. Penentuan kebutuhan informasi

4. Asal dan informasi yang disajikan

\section{Analisis kebutuhan}

Tahap ini dilakukan beberapa analisis kebutuhan sistem meliputi:

\section{a. Output yang diinginkan}

Output yang diinginkan dari web based accited design pada dimensi saluran irigasi yaitu pengguna akan mendapatkan informasi tentang aplikasi bentuk dimensi saluran, dan berbagai bahan dinding saluran berdasarkan data yang di input oleh pengguna.

b. Data yang dibutuhkan

Data yang dibutuhkan yaitu data debit rencana, kecepatan aliran, koefisien kekasaran Manninguntuk dinding saluran, koefisien kekasaran Strickler untuk saluran tanah, tinggi jagaan dan kemiringan saluran. 
c. Keperluan perangkat keras

Xampp control panel v3.2.2. sebagai web server lokal untuk mengeksekusi sistem dalam jaringan internet. Terdiri dari Web Scripting Javascript sebagai bahasa pemograman berfungsi sebagai pengolah data pada server. Web Server yang digunakan adalah Apache/2.4.27.

d. Perencanaan hidrolis

Perencanaan hidrolis yang dilakukan dalam penentuan dimensi saluran trapesium dan persegi yaitu:

1) Debit Rencana

$$
Q=\frac{c N F R A}{e}
$$

Keterangan:

Q : Debit rencana (1/s)

c : Koefisien pengurangan (tidak berdimensi).

NFR : Kebutuhan bersih (netto) air di sawah (mm/hari)

A : Luas daerah yang diairi (ha)

e : Efisiensi irigasi (0-1)

2) Penampang saluran terbuka

Penampang paling ekonomis adalah penampang yang memiliki debit Q maksimum ' pada luasan (A) tertentu. Suatu tampang akan menghasilkan debit maksimum bila nilai $\mathrm{R}$ maksimum atau nilai $\mathrm{P}$ minimum. Dari rumus debit yang digunakan maka menghitung nilai luasan yaitu:

$$
A=\frac{Q}{v}
$$

3) Perbandingan $b / h$

Hubungan b/h pada Lampiran Tabel (b). terhadap luas penampang basah saluran $A=(b+m h) h$, maka tinggi air (h) dapat ditentukan dan dilihat pula nilai lebar dasar saluran (b). Sedangkan untuk saluran segi empat dengan rumus $A=$ $2 h^{2}$ dengan $h$ yaitu tinggi air.

4) Menghitung gradient hidrolis, dari rumus:

Keterangan:

$$
S=n^{2} \times v^{2} / R^{4 / 9}
$$

$\mathrm{S}$ : Kemiringan saluran.

$\mathrm{v}$ : Kecepatan aliran standar, $(\mathrm{m} / \mathrm{s})$.

$\mathrm{n}$ : Koefisien kekasaran Manning.

$\mathrm{R}$ : Jari-jari hidrolis (m)

\section{Tahapan Pengembangan Web}

Pada pembuatan web-based dilakukan berdasarkan tahapan sebagai berikut:

a. Membuat Script

Script atau file teks, yang dibuat dengan menggunakan program editor file teks biasa yaitu visual studio code atau pun lainnya.

b. Perancangan algoritma

Algoritma yang dibuat yaitu rumus dimensi saluran dengan algoritma debit rencana, potongan melintang, debit saluran, jari-jari hidrolis, keliling basah, gradient hidrolis dan tinggi saluran.

c. Membuat Fungsi

Fungsi (function) merupakan serangkaian script atau kode yang mempunyai kegunaan khusus dan tertentu merupakan seurutan atau serangkaian kode yang sering dipakai. Fungsi yang digunakan yaitu fungsi built-in (Built in Function). Fungsi built-in yang digunakan yaitu fungsi untuk matematika.

d. Content dan design saluran

Menyiapkan content dan design web berupa informasi yang diperlukan berkaitan dengan bangunan saluran irigasi. Content yang akan dimuat ke dalam website berupa teks dan kumpulan foto. Sedangkan design berupa tampilan yang dibuat agar website terlihat indah dan menarik perhatian pengunjung website. Model navigasi dasar yang dgunakan yaitu hierarchical navigation dengan model top-down design. terdapat satu node yang menjadi homepage. Kemudian hompage tersebut dibuat beberapa cabang ke halaman-halaman utama.

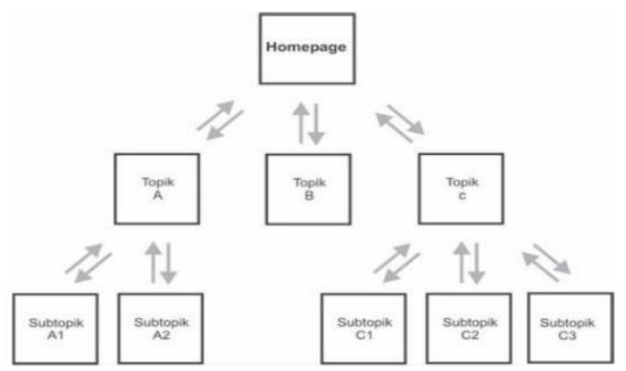

Gambar 1. Struktur navigasi hierarchical model 


\section{Implementasi}

Implementasi merupakan proses pembuatan program berdasarkan desain program yang telah ditentukan. Tahapan ini mencakup pengujian sistem dan jaringan, pengujian program, dan membuatkan alamat domain untuk program yang telah dibuat.

\section{HASIL DAN PEMBAHASAN}

\section{Gambaran Umum Website}

Web web-based computer assisted design pada dimensi saluran ini memiliki model navigasi dasar dengan desain hierarchical navigation dengan model topdown design. Terdiri dari satu menu home yang menjadi homepage. Dari hompage tersebut maka percabangan dari menu utama ke halaman-halaman dibawanya. Website ini terdiri dari tujuh content dimana beberapa content memiliki halaman drop dawn

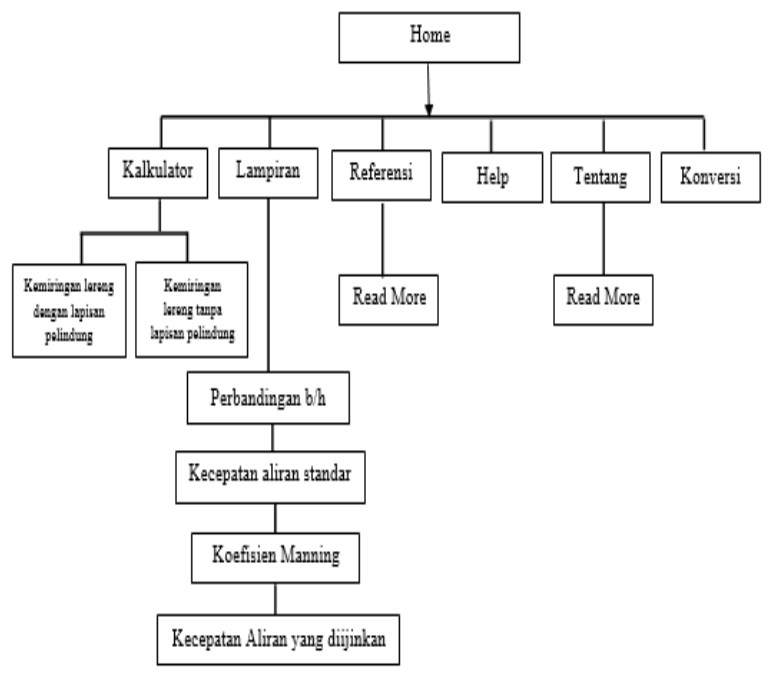

Gambar 2. Struktur Link Website

Teknologi website yang di buat bersifat statis dimana pengguna tidak dapat mengubah konten secara langsung menggunakan browser, namun harus melakukan code ulang. Data yang digunakan pada sistem ini bersumber dari pengguna website atau yang dikenal dengan data input, data input yang di gunakan yaitu data debit dengan satuan $\mathrm{m}^{3} / \mathrm{s}$ dan kecepatan dengan satuan $\mathrm{m} / \mathrm{s}$ sehingga menghasilkan nilai luas penampang dengan satan $\mathrm{m}^{2}$.
Table 1. Gambaran umum interkasiinteraksi yang terjadi di dalam sistem.

\begin{tabular}{|c|c|c|}
\hline No & Aksi & Hasil \\
\hline 1. & $\begin{array}{l}\text { Membuat alamat } \\
\text { domain }\end{array}$ & $\begin{array}{l}\text { Website dapat di } \\
\text { akses oleh pengguna } \\
\text { secara umum. }\end{array}$ \\
\hline 2. & $\begin{array}{l}\text { Website di buat } \\
\text { statis }\end{array}$ & $\begin{array}{l}\text { Konten tidak dapat } \\
\text { diperbaharui secara } \\
\text { flexible }\end{array}$ \\
\hline 3. & $\begin{array}{l}\text { Terdapat beberapa } \\
\text { bagian }\end{array}$ & $\begin{array}{l}\text { Setiap konten } \\
\text { memiliki isi yang } \\
\text { berbeda }\end{array}$ \\
\hline 4. & $\begin{array}{l}\text { Di buat konten } \\
\text { kalkulator dengan } \\
\text { dua drop dawn } \\
\text { yaitu kemiringan } \\
\text { dengan saluran } \\
\text { pasangan dan } \\
\text { kemiringan } \\
\text { dengan dengan } \\
\text { saluran tanpa } \\
\text { pasangan }\end{array}$ & $\begin{array}{l}\text { Pengguna dapat } \\
\text { menghitung dimensi } \\
\text { saluran irigasi dengan } \\
\text { penampang trapezium } \\
\text { dan segiempat. }\end{array}$ \\
\hline 5. & Content konversi & $\begin{array}{l}\text { Pengguna dapat } \\
\text { mengkonversi dari } \\
\text { satu jenis satuan ke } \\
\text { satuan lain }\end{array}$ \\
\hline 6. & Content referensi & $\begin{array}{l}\text { Pengguna dapat } \\
\text { menemukan } \\
\text { informasi umum } \\
\text { terkait dengan } \\
\text { bangunan saluran } \\
\text { irigasi }\end{array}$ \\
\hline 7. & Content Tentang & $\begin{array}{l}\text { Menampilkan data } \\
\text { pribadi pembuat } \\
\text { website }\end{array}$ \\
\hline 8. & Content Bantuan & $\begin{array}{l}\text { Menampilkan } \\
\text { petunjuk dalam } \\
\text { penggunaan berbagai } \\
\text { content yang } \\
\text { ditampilkan }\end{array}$ \\
\hline
\end{tabular}

\section{Pengujian Sistem}

Pengujian website dilakukan agar mengetahui sejauh mana keberhasilan website yang telah dibuat. Selain itu, tahapan pengujian dilakukan dengan tujuan untuk menghidari kesalahan-kesalahan pada web yang dibuat seperti kesalahan kode program atau kesalahan dalam menginput data.

Pada tahap pengujian website dilakukan penginputan terhadap beberapa sampel data. Hal ini dilakukan untuk melihat apakah website telah bekerja sesuai dengan perancangan dan layak untuk digunakan.

Hasil pengujian pada black box dari website ini dapat di lihat pada tabel hasil pengujian fungsional berikut: 
Tabel 2. Pengujian fungsional website

\begin{tabular}{|c|c|c|c|}
\hline No. & Poin Pengujian & Respon system & Hasil \\
\hline 1. & $\begin{array}{l}\text { Mengakses } \\
\text { halaman }\end{array}$ & $\begin{array}{l}\text { Masuk ke } \\
\text { halaman awal } \\
\text { website }\end{array}$ & $\sqrt{ }$ \\
\hline 2. & $\begin{array}{l}\text { Membuka } \\
\text { halaman utama } \\
\text { website }\end{array}$ & $\begin{array}{l}\text { Menampilkan } \\
\text { tampilan pembuka } \\
\text { dari website }\end{array}$ & $\sqrt{ }$ \\
\hline 3. & $\begin{array}{l}\text { Membuka menu } \\
\text { kalkulator }\end{array}$ & $\begin{array}{l}\text { Menampilkan } \\
\text { desain kalkulator } \\
\text { dari dua jenis } \\
\text { dimensi saluran } \\
\text { yaitu trapezium } \\
\text { dan segiempat }\end{array}$ & $\sqrt{ }$ \\
\hline 4. & $\begin{array}{l}\text { Mengisi form } \\
\text { yang ada pada } \\
\text { menu kalkulator }\end{array}$ & $\begin{array}{l}\text { Menampilkan } \\
\text { hasil perhitungan } \\
\text { yang di isi pada } \\
\text { form }\end{array}$ & $\sqrt{ }$ \\
\hline 5. & $\begin{array}{l}\text { Membuka menu } \\
\text { konversi }\end{array}$ & $\begin{array}{l}\text { Menampilkan } \\
\text { hasil konversi dari } \\
\text { satu jenis satuan } \\
\text { ke satuan lainnya }\end{array}$ & $\sqrt{ }$ \\
\hline 6. & $\begin{array}{l}\text { Membuka menu } \\
\text { referensi }\end{array}$ & $\begin{array}{l}\text { Menampilkan } \\
\text { informasi tentang } \\
\text { debit rencana, } \\
\text { saluran irigasi, } \\
\text { dan karakteristik } \\
\text { saluran }\end{array}$ & $\sqrt{ }$ \\
\hline 7. & $\begin{array}{l}\text { Membuka menu } \\
\text { tentang }\end{array}$ & $\begin{array}{l}\text { Menampilkan } \\
\text { biografi pembuat } \\
\text { website }\end{array}$ & $\sqrt{ }$ \\
\hline 8. & $\begin{array}{l}\text { Membuka menu } \\
\text { Bantuan }\end{array}$ & $\begin{array}{l}\text { Menampilkan } \\
\text { petunjuk } \\
\text { penggunaan } \\
\text { website }\end{array}$ & $\sqrt{ }$ \\
\hline
\end{tabular}

\section{Implementasi Sistem pada Server}

File sistem di uji coba pada server yang dapat di akses melalui 103.195.142.45/ student/file_baru/untuk pengguna, sistem ini dapat di akses oleh masyarakat umum akan tetapi sistem ini bersifat statis yakni apabila ada perubahan terhadap data maka di lakukan code ulang. Web assisted design ini terbagi menjadi beberapa menu antara lain:

\section{Menu Home}

Dengan mengakses 103.195.142.45/ student/file_baru/ maka pengguna website akan di arahkan ke halaman seperti berikut:

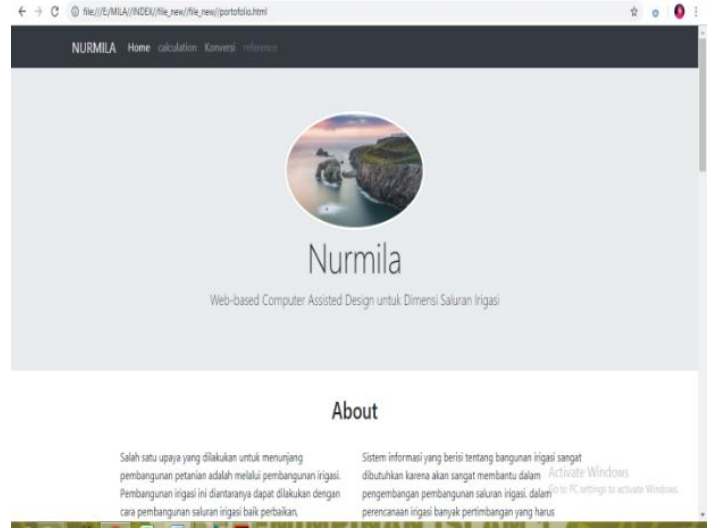

\section{Gambar 3. Halaman awal}

Pada halaman awal, publik dapat melihat tampilan foto profil pembuat web dalam bentuk gambar. Dalam menu ini terdiri dari tampilan About, portfolio, dan contact dengan adanya tampilan awal ini membuat pengguna dapat memahami isi dari menu- menu lainnya. Pada tampilan About berisi tentang latar belakang pembuatan web assisted design ini. sedangkan pada tampilan portfolio menampilkan gambar tentang dimensi saluran.

2. Menu kalkulator

Pada menu kalkulator terdapat dua jenis saluran yang dapat di hitung dimensinya yaitu saluran dengan kemiringan saluran pasangan dan kemiringan dengan saluran tanpa pasangan. Pada menu kalkulator ini ditampilkan dengan system dropdawn sehingga pengguna lebih mudah memilih jenis salurannya. Pada setiap menu terdapat dua jenis perhitungan yang ditampilkan yaitu perhitungan saluran dengan penampang trapezium dan penampang segiempat.

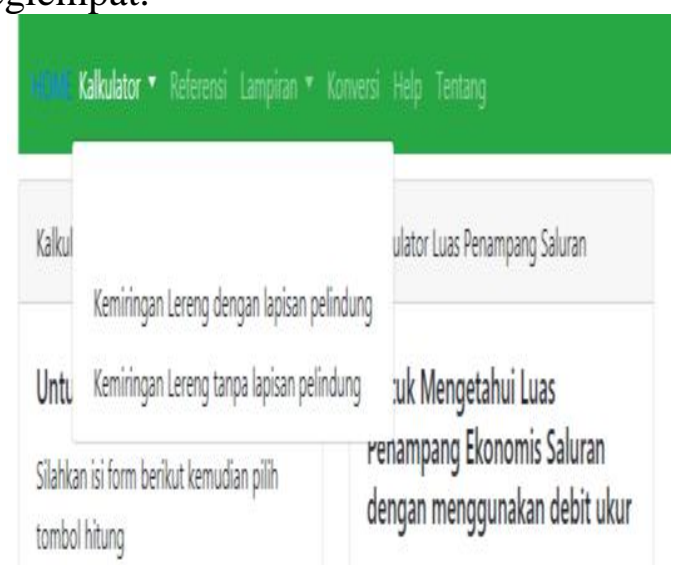

Gambar 4. Menu kalkulator dengan dropdown 
Dengan menginput nilai debit saluran dan nilai kecepatan maka akan menghasilkan nilai luas penampang. Apabila nilai debit tidak diketahui maka dapat menghitung di form kalkulator debit rencana. Jika data debit yang diinput tidak sesuai dengan ketentuan pedoman perencanaan irigasi yang telah diinput maka tidak dapat tereksekusi atau $U N K N O W N$.

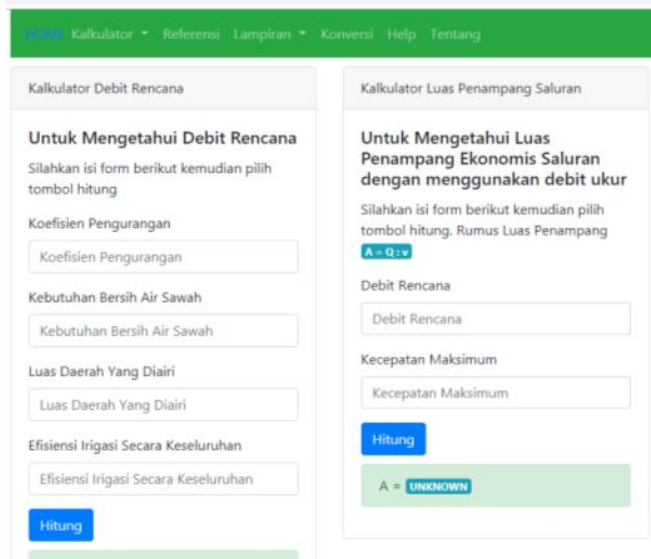

Gambar 5. Menu kalkulator debit rencana dan luas penampang saluran.

Setelah mendapatkan nilai luas penampang saluran, maka didapatkan nilai koefisien manning, koefisien Strickler, perbandingan $\mathrm{b} / \mathrm{h}$, tinggi jagaan, kemiringan talud 1 (untuk saluran pasangan), dan kemiringan talud 2 untuk saluran tanpa pasangan. Data tersebut diperoleh dari Direktorat Jenderal Sumber Daya Air KP 03-Saluran, (2013).

Pada Gambar 5 setelah menginput nilai debit rencana $23 \mathrm{~m}^{3} / \mathrm{s}$, maka menghasilkan nilai koefisien Strickler 50,001, koefisien manning 0,02, perbandingan $\mathrm{b} / \mathrm{h} 8$, kemiringan talud 1 (saluran dengan pasangan) $2 \mathrm{~m}$, kemiringan talud 2 (saluran tanpa pasangan) $1,5 \mathrm{~m}$, dan tinggi jagaan $(\mathrm{fb}) 0,75 \mathrm{~m}$.

Pada Gambar 6 setelah menginput nilai debit rencana $23 \mathrm{~m}^{3} / \mathrm{s}$, maka menghasilkan nilai koefisien Strickler 50,001, koefisien manning 0,02, perbandingan $\mathrm{b} / \mathrm{h} 8$, kemiringan talud 1 (saluran dengan pasangan) $2 \mathrm{~m}$, kemiringan talud 2 (saluran tanpa pasangan) $1,5 \mathrm{~m}$, dan tinggi jagaan (fb) $0,75 \mathrm{~m}$.

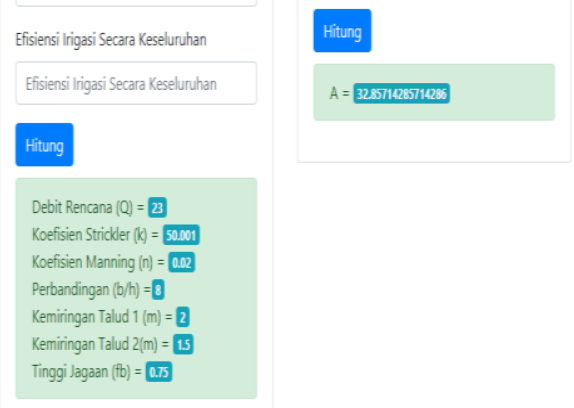

Gambar 6. Hasil perhitungan luas penampang

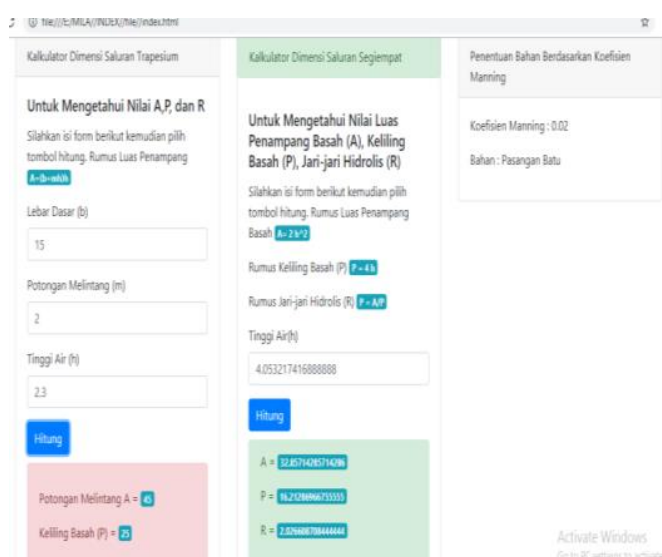

Gambar 7. Tampilan kalkulator dimensi saluran trapezium dan segiempat

\section{Menu Referensi}

Pada menu referensi yang di tampilkan pada Gambar 8. akan muncul pertama kali tampilan beberapa card body yang mewakili setiap informasi yang dijelaskan dalam card. Informasi-informasi yang ditampilkan yaitu saluran irigasi secara umum, debit rencana, karakteristik saluran, perencanaan saluran dan sebagainya.

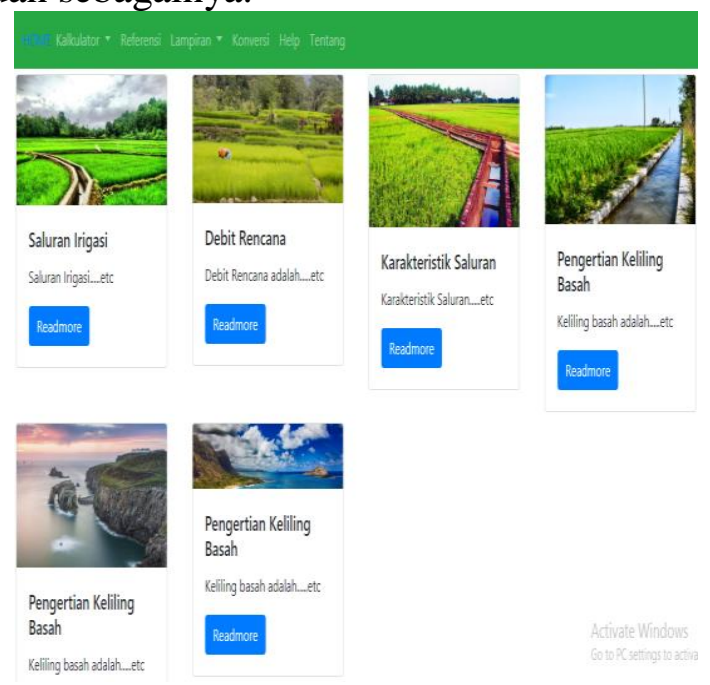

Gambar 8. Menu referensi 
Tampilan yang dihasilkan pada setiap card body akan menampilkan beberapa paragraf yang berisi tentang informasi dari setiap card. Tampilan yang dihasilkan dapat dilihat pada Gambar 9.

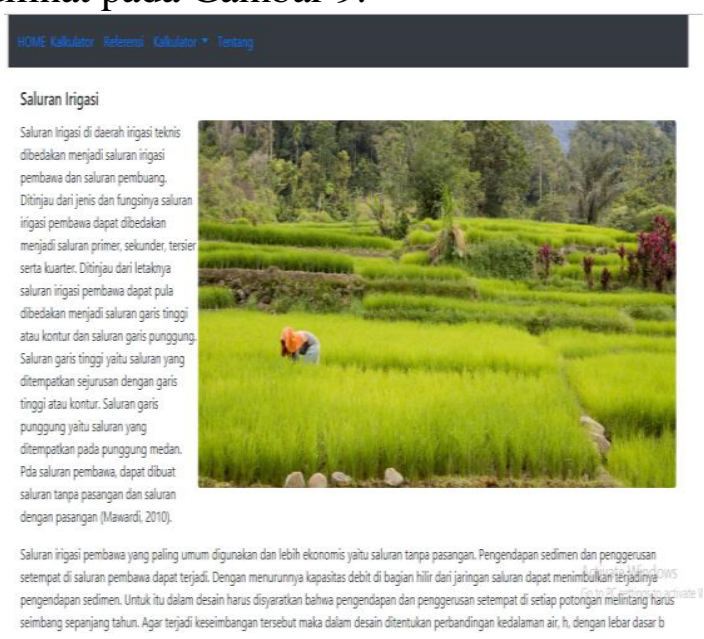

Gambar 9. Halaman referensi saluran irigasi

4. Menu konversi

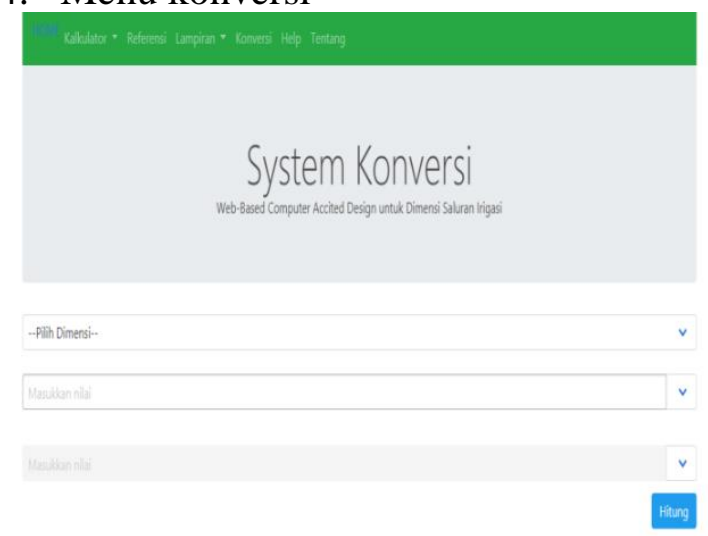

Gambar 10. Menu konversi.

Menu konversi di buat agar pengguna website dapat mengkonversi dari satuan 1/s/ha ke satuan $\mathrm{mm} / \mathrm{ha}$ tanpa harus keluar dari halaman website. Pada bagian ini diaplikasikan menu drop down, sehingga pengguna dapat memilih dengan mudah jenis satuan yang akan di konversi dengan cara drop maupun down.

Menu konversi ini di buat agar pada proses perhitungan dimensi pada menu kalkulator tidak mengalami kesalahan karena adanya perbedaan satuan yang dapat menyebabkan kesalahan pada hasil perhitungan.
Jurnal AgriTechno. Vol. 11 (2): 155-162

https://doi.org/ 10.20956/at.v11i2.138

5. Halaman Help

Pada menu ini, menampilkan tentang bagaimana menggunakan website ini, dan cara menggunakan menu kalkulator. Dengan menu ini maka pengguna dapat lebih mudah untuk melakukan perhitungan di menu kalkulator.

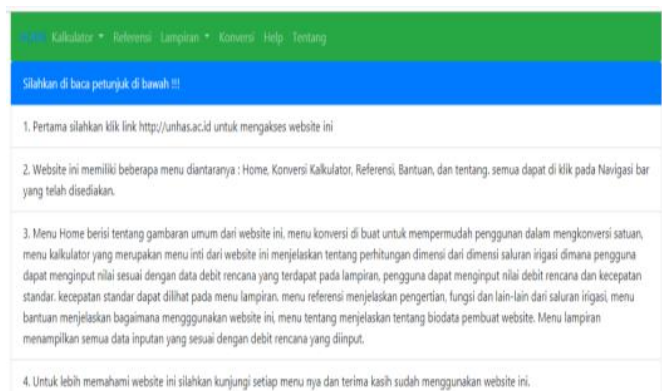

Gambar 11. Halaman Help

6. Halaman lampiran

Halaman lampiran tabel memuat tentang data yang diinput ke dalam perhitungan. Menu ini disediakan agar pengguna website dapat lebih memahami data yang sesuai dengan perencanaan saluran ekonomis. Apabila pada menu Kalkulator terdapat nilai Unknown, maka data tidak sesuai dengan data yang terdapat pada Lampiran. Jenis navbar yang digunakan yaitu navbar dropdawn dengan menampilkan semua lampiran.

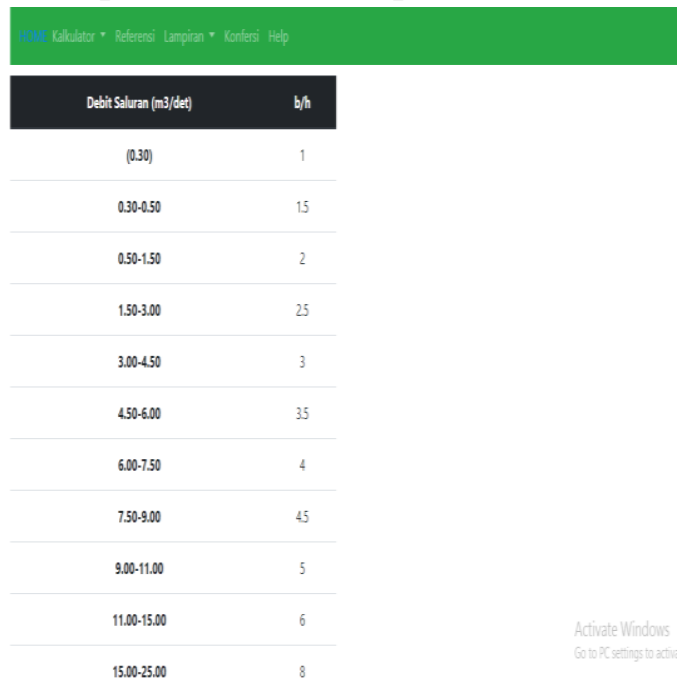

Gambar 12. Halaman lampiran tabel.

\section{Menu Tentang}

Menu tentang berisi tentang riwayat hidup pembuat website. Menu yang pertama 
kali ditampilkan yaitu data singkat penulis kemudian untuk menampilkan data selanjutnya maka klik learn more.

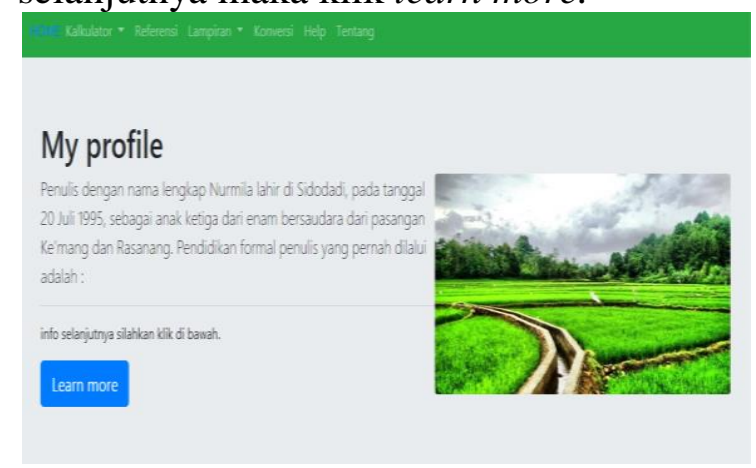

Gambar 13. Halaman Tentang

\section{KESIMPULAN}

Berdasarkan Web assisted design yang telah dihasilkan, maka dapat disimpulkan bahwa:

1. Proses penampilan halaman web dengan menggunakan bahasa pemrograman HTML dapat berjalan dengan baik ketika diujikan pada jaringan lokal.

2. Web assisted design dapat digunakan untuk menghitung luas penampang saluran, keliling basah, tinggi saluran dan gradien hidrolis.

3. Web assisted design dapat digunakan dalam perencanaan saluran irigasi yang ekonomis dengan menampilkan bahan dinding saluran yang akan digunakan untuk membangun saluran.

\section{DAFTAR PUSTAKA}

Direktorat Jenderal Sumber Daya Air dan Direktorat Irigasi dan Rawa.2013. Standar Perencanaan Irigasi KP 03 (Saluran). Kementerian Pekerjaan Umum Direktorat Jenderal Sumber Daya Air: Jakarta.

Effendy. 2012. Disain Saluran Irigasi. Politeknik Negeri Surabaya: Palembang.

Haris, TH., Alfian S., dan Muthia A. 2016. Perencanaan Dimensi Ekonomis, Saluran Primer Daerah Irigasi di Bunga Raya. Universitas Lancang
Kuning: Jurnal Teknik Sipil, Vol 2, No.1.

Kamiana, I Made. 2011. Tenis Perhitungan Debit Rencana Bangunan Air. Graha Ilmu: Yogyakarta 